Cómo citar: J. Rivera, “Editorial. La agricultura familiar, una apuesta para la construcción de contextos rurales diferentes", Inventum, vol. 14, no. 26, pp. 79-80. doi: 10.26620/uniminuto. inventum.14.26.2019.79-80

Editorial: Corporación Universitaria Minuto de Dios - UNIMINUTO.

ISSN: $1909-2520$

elSSN: $2590-8219$

Fecha de recibido: mayo 01 de 2019 Fecha de aprobado: junio 30 de 2019 Fecha de publicación: septiembre 01 de 2019

Conflicto de intereses: los autores han declarado que no existen intereses en competencia.
EDITORIAL

\section{LA AGRICULTURA FAMILIAR, UNA APUESTA PARA LA CONSTRUCCIÓN DE CONTEXTOS RURALES DIFERENTES}

La edición $n .^{\circ} 26$ de la revista INVENTUM hace énfasis en la Especialización en Agricultura Familiar que surge de las iniciativas de los profesores del programa de Ingeniería Agroecológica de la Corporación Universitaria Minuto de Dios - UNIMINUTO, quienes desde su experiencia y experticia articulan la propuesta en la línea de investigación de la Facultad de Ingeniería denominada "Manejo de los recursos naturales" y que cuenta con la aprobación del Ministerio de Educación Nacional de Colombia.

Este programa académico se considera como una perspectiva holística frente a las dinámicas y complejidades actuales del contexto rural en nuestro país; y pretende formar especialistas que mitiguen y coadyuven en la construcción de una ruralidad más incluyente con el fin de proponer e investigar alternativas encaminadas a resolver las dificultades del sector rural y establecer canales de comunicación que permitan cerrar las brechas existentes entre lo rural y urbano.

La agricultura familiar se justifica desde diferentes vertientes tales como: la búsqueda de políticas rurales que trasciendan en lo sectorial; el año 2014 como momento internacional de la agricultura familiar; la participación de UNIMINUTO en la RENAF; la campaña permanente por la agricultura familiar en Colombia (lobby de organismos multilaterales -FAO/IICA) y por políticas diferenciales para la agricultura familiar; la mesa de trabajo con el Ministerio de Agricultura y Desarrollo Rural, FAO y RENAF para políticas públicas diferenciales en favor de la agricultura familiar y el interés renovado a nivel nacional por la ruralidad en el posconflicto.

Su fundamento teórico se basa en la agroecología como forma de agricultura sostenible; la economía solidaria, especialmente en relación al comercio local y justo y en estrategias solidarias de financiación productiva; las organizaciones sociales en el sector rural; los procesos constitutivos de incidencia y cooperación; el desarrollo rural con enfoque territorial; las nuevas relaciones campo-ciudad; las metodologías participativas para generar procesos autogestionarios de transformación productiva y social; y el desarrollo sostenible.

Son tres áreas desde las cuales se desarrolla el programa de especialización: la agroecología y la economía solidaría, las políticas públicas y la investigación. Cada una de ellas abarca a su vez diferentes cursos desde los cuales los especialistas pueden profundizar sobre un aspecto de interés. De la misma manera, dentro del programa se cuenta un amplio referente teórico 
presentado en libros, material metodológico y artículos, que potencializan la construcción del conocimiento científico en el contexto rural, y por ende, de la agricultura familiar.

Con todos los insumos anteriormente señalados, se desea a los estudiantes participantes que abren esa corte, lo mejor de lo mejor en este nuevo camino que se constituye como una apuesta en marcha para la construcción de un nuevo país y el desarrollo de propuestas e iniciativas que posibiliten la construcción de planes de acción, estrategias participativas de las comunidades, inclusión del sector rural en el urbano, entre otros, etc. En la búsqueda por solucionar y generar cambios significativos para un nuevo país, se refleja este nuevo aporte de UNIMINUTO a la sociedad que pretende transformar los paradigmas existentes en los diferentes territorios del país y concebir una agricultura sostenible. Recordemos que las palabras del padre Rafael García Herreros, que encontramos en el libro Constructores de la nueva Colombia: "La Universidad Minuto de Dios será una bellísima universidad que cubrirá las necesidades del noroccidente de Bogotá. Queremos hacer una universidad cristiana... Esta universidad recalcará especialmente lo social. Vamos a formar ingenieros sociales que sean capaces de empeñarse en el desarrollo de los pueblos de Colombia. Allí se formarán los pedagogos que orientarán la nueva población de Colombia... Nuestra universidad va aportar algo muy importante hacia la nueva Colombia".

Julio César Rivera Rodríguez

Editor 